\title{
Late-Life Decline in Well-Being Across Adulthood in Germany, the United Kingdom, and the United States: Something Is Seriously Wrong at the End of Life
}

\author{
Denis Gerstorf \\ Pennsylvania State University and German \\ Institute for Economic Research \\ Guy Mayraz \\ London School of Economics \\ Ulman Lindenberger \\ Max Planck Institute for Human Development
}

\author{
Nilam Ram \\ Pennsylvania State University and Max Planck \\ Institute for Human Development \\ Mira Hidajat \\ Pennsylvania State University \\ Gert G. Wagner \\ German Institute for Economic Research \\ and Berlin University of Technology
}

\author{
Jürgen Schupp \\ German Institute for Economic Research and Free University of Berlin
}

\begin{abstract}
Throughout adulthood and old age, levels of well-being appear to remain relatively stable. However, evidence is emerging that late in life well-being declines considerably. Using long-term longitudinal data of deceased participants in national samples from Germany, the United Kingdom, and the United States, we examined how long this period lasts. In all 3 nations and across the adult age range, well-being was relatively stable over age but declined rapidly with impending death. Articulating notions of terminal decline associated with impending death, we identified prototypical transition points in each study between 3 and 5 years prior to death, after which normative rates of decline steepened by a factor of 3 or more. The findings suggest that mortality-related mechanisms drive late-life changes in well-being and highlight the need for further refinement of psychological concepts about how and when late-life declines in psychosocial functioning prototypically begin.
\end{abstract}

Keywords: selective mortality, successful aging, differential aging, psychosocial factors, multiphase growth model

Empirical evidence indicates that individuals throughout adulthood and old age typically report being satisfied with their lives (see Diener, Lucas, \& Scollon, 2006). The objective of this study was to corroborate and extend recent studies that challenge this prevailing view (Gerstorf, Ram, Estabrook, et al., 2008; Gerstorf, Ram, Röcke, Lindenberger, \& Smith, 2008; Mroczek \& Spiro, 2005). Drawing from notions of terminal decline, we argue that individuals usually have enough resources to maintain a sense of well-being, even in the face of age-related risks for social losses and declining health (Guralnik, 1991; Suzman, Willis, \& Manton, 1992). At some point before death, however, additional mortalityrelated burdens and systemic dysfunction may become too difficult to cope with, and functionality declines straight into death (Kleemeier, 1962; Riegel \& Riegel, 1972). Despite these notions
Denis Gerstorf, Department of Human Development and Family Studies, Pennsylvania State University, and German Socio-Economic Panel Study, German Institute for Economic Research (DIW Berlin), Berlin, Germany; Nilam Ram, Department of Human Development and Family Studies, Pennsylvania State University, and Max Planck Institute for Human Development, Berlin, Germany; Guy Mayraz, London School of Economics, London, England; Mira Hidajat, Gerontology Center, Pennsylvania State University; Ulman Lindenberger, Max Planck Institute for Human Development; Gert G. Wagner, German Socio-Economic Panel Study, DIW Berlin, and Berlin University of Technology, Berlin, Germany; Jürgen Schupp, German Socio-Economic Panel Study, DIW Berlin, and Free University of Berlin, Germany.
The content is solely the responsibility of the authors and does not necessarily represent the official views of the funding agencies.

We are grateful for the support provided by the National Institute on Aging (Grants RC1-AG035645, R21-AG032379, and R21-AG033109), DIW Berlin, the Max Planck Society, and the Social Science Research Institute at Pennsylvania State University. Additional support was provided by grants from the Federal Ministry of Education and Research (Germany) to Jürgen Schupp and Gert G. Wagner.

Correspondence concerning this article should be addressed to Denis Gerstorf, Department of Human Development and Family Studies, Pennsylvania State University, 118 Henderson Building, University Park, PA 16802. E-mail: gerstorf@psu.edu 
having been around for several decades, specific conceptual predictions and empirical descriptions regarding whether and how terminal decline involves well-being have not yet been developed. Our purpose here was to use longitudinal data from three nationally representative samples to ask two questions about terminal decline in well-being: Do normative late-life changes in well-being across the adult life span conform to a pattern expected by terminal decline? If so, when does terminal decline prototypically begin?

Theories of self-regulation and life span development both propose that well-being remains largely stable across adulthood and old age. For example, models of hedonic adaptation suggest that changing life circumstances have only short-term effects on well-being, after which people quickly adapt and return to their characteristic levels or "set points" (Brickman \& Campbell, 1971). Similarly, socioemotional selectivity theory, highlighting positive aspects of aging, contends that a limited future time perspective prompts a motivational shift toward regulating emotional states in order to optimize well-being (Carstensen, 2006). Because older adults typically perceive time as more finite than younger adults, they are often more motivated to achieve emotional meaning and satisfaction, which in turn results in them being as happy as (if not happier than) younger adults. These and other theories (e.g., action theory; Brandstädter, 1999) conjointly suggest that the selfregulation system is highly efficient in helping people adapt to a variety of (changes in) life circumstances.

A large body of literature across most of the world attests to the above proposals that well-being remains stable throughout adulthood (see Argyle, 1999; Carstensen, Pasupathi, Mayr, \& Nesselroade, 2000; Diener et al., 2006; Diener, Suh, Lucas, \& Smith, 1999; Kunzman, Little, \& Smith, 2000; Larson, 1978; Mroczek \& Kolarz, 1998; Myers, 1992). Diener and Suh (1997), in reviewing cross-sectional results obtained in age-heterogeneous adult samples from multiple nations, concluded that life satisfaction is relatively stable across age cohorts in most societies. Longitudinal studies also provide evidence of relative stability in various facets of well-being across adulthood. For example, Charles, Reynolds, and Gatz (2001) used 23-year longitudinal data from the United States and found stability in positive affect across most of adulthood, with only slight declines being noted after age 65 . Similar results have been found in longitudinal samples from the United States (Costa et al., 1987; Griffin, Mroczek, \& Spiro, 2006) and Europe (Haynie, Berg, Johannson, Gatz, \& Zarit, 2001; Kunzmann, 2008; Schilling, 2006). In sum, the general pattern of age-related stability of well-being, or small decreases over time, is well documented by both large-scale surveys and longitudinal studies of change and has been found consistently for different facets of well-being.

Recently, theory and evidence of stability in well-being across adulthood has been complemented by evidence suggesting that individuals who experience steep declines or report low levels of well-being are at higher risk of dying (Danner, Snowdon, \& Friesen, 2001; Levy, Slade, Kunkel, \& Kasl, 2002; Maier \& Smith, 1999; Mroczek \& Spiro, 2005). The conundrum of stability versus decline may be indicative of a terminal decline process (see Birren $\&$ Cunningham, 1985). Conceptual notions of terminal decline implicate mortality as a major force underlying developmental change in the last years of life (Kleemeier, 1962). The basic idea is that the mortal event serves as an "absorbing state" that drags individual function, including well-being, down. Empirical sup- port has primarily accumulated in the cognitive aging domains (see Bäckman \& MacDonald, 2006; Small \& Bäckman, 1999), but initial evidence has also recently been documented for well-being among now-deceased 70- to 100-year-old Germans (Gerstorf, Ram, Estabrook, et al., 2008; Gerstorf, Ram, Röcke, et al., 2008). Our intent here was to examine further whether the terminal decline phenomena replicates and generalizes to mortal events that occur across the entire adult life span, rather than just in old age. To do so, we made use of well-being measures that were included in three national panel studies.

A crucial component of the terminal decline hypothesis is that there are two phases of change, a preterminal phase of relative stability or gradual age-related decline and a terminal phase of steep, proximate-to-death decline (see Bäckman \& MacDonald, 2006). The concept, however, lacks specificity regarding the timing of when such a transition to the terminal phase happens (e.g., "months to years" before death; Birren \& Cunningham, 1985, p. 21). Applying recent developments in multiphase growth modeling, researchers have started to empirically articulate and test the concept and to localize the onset of terminal decline. In the cognitive aging domain, empirical reports place the transition to the terminal phase between 4 years (Wilson, Beckett, Bienias, Evans, \& Bennett, 2003) and 8 years (Sliwinski et al., 2006) prior to death. Initial studies of terminal decline in well-being in old age located the prototypical transition 4 years before death (Gerstorf, Ram, Estabrook, et al., 2008), after which well-being dropped, on average, nearly a full standard deviation. Our study adds to those initial explorations by empirically estimating the onset of terminal decline in well-being using a much broader age spectrum of decedents from three large national samples, and may, we hope, prompt further precision and refinement of concepts about when, why, in which domains, and how the terminal phase of life begins and proceeds.

In sum, we used long-term longitudinal data of decedents from three nationally representative studies to evaluate whether the terminal decline phenomena extend to aspects of well-being and to determine when such terminal declines may be expected to begin. Specifically, we evaluate whether two-phase models of change that articulate preterminal and terminal phases of decline provide a better description of long-term changes in well-being across the adult life span than do typical examinations of age-related change. Three national samples from Germany, the United Kingdom, and the United States were used to obtain a normative description of whether and how well-being changes across adulthood, from middle age until death.

\section{Method}

To examine within-person change in well-being, we fitted separate growth curve models to longitudinal data from now-deceased participants in the German Socio-Economic Panel Study (SOEP; 22 annual waves from 1984 to 2005), the British Household Panel Study (BHPS; 15 annual waves from 1991 to 2005), and the U.S. Health and Retirement Study (HRS; six biannual waves from 1994 to 2004). In-depth descriptions of these longitudinal panel studies can be found in prior publications (SOEP, Wagner, Frick, \& Schupp, 2007; BHPS, Taylor, Brice, Buck, \& Prentice-Lane, 2008; HRS, Burkhauser \& Gertler, 1995). Details relevant to this investigation are given below. 


\section{Participants and Procedure}

All three studies are national panels with data primarily collected via face-to-face (SOEP, BHPS) or telephone interviews (HRS). Here we made use of data obtained from all study participants (decedents) who had died by 2006. Descriptive information is presented in Table 1. A few aspects are highlighted. First, included in each sample were more than 2,000 men and women who had died during adulthood, with the average age at death falling between 70 and 80 years of age. Second, between-wave attrition has been relatively low, and individuals participated in an average of 3 or more waves, with more than half of each sample contributing three or more data points. Third, on average, deaths occurred between 6 and 9 years after participants' initial assessment and around 2 years after their last assessment. Finally, in each study, participants contributed more than 10,000 observations that simultaneously span the $25-100$ years age range and the last 13 or more years prior to death. Importantly, the large majority of these observations were provided between 50 and 90 years of age ( $85 \%$ or greater across studies) and in the last 10 years of life $(75 \%$ or greater across studies).

\section{Measures}

Well-being. In the SOEP, well-being was measured with the item "How satisfied are you currently with your life, all things considered?" answered on a scale from 0 (completely unsatisfied) to 10 (completely satisfied). Responses are taken as an indication of cognitive-evaluative aspects of well-being (Fujita \& Diener, 2005). BHPS participants completed the General Health Questionnaire (Goldberg, 1978), a measure indicative of emotionalaffective aspects of well-being (Hu, Stewart-Brown, Twigg, \& Weich, 2007). The scale was a sum of 12 items (e.g., "Have you recently been feeling reasonably happy, all things considered?") that were answered on a scale of 1 (more so than usual) to 4 (much less than usual). HRS participants responded to eight items from the Center for Epidemiologic Studies Depression Scale (Radloff, 1977) asking whether they had experienced feelings of being depressed, happy, or sad either much of the time during the past week (1) or not much of the time during the past week (0).

Although the measures assessed varying degrees of cognitiveevaluative (SOEP) or emotional-affective aspects of well-being (BHPS, HRS), all were taken as the available indicator of a general well-being construct. Across studies, item responses and summary scores were coded so that higher scores indicate higher levels of well-being, and were standardized, within each study, to a $T$ metric $(M=50, S D=10)$, with the total set of observations within a given study serving as the reference frame for the rescaling (SOEP, on a $0-10$ scale: $M=6.65, S D=2.26$; BHPS, on a $0-36$ scale: $M=23.91, S D=5.74$; HRS, on a $0-8$ scale: $M=6.03, S D=$ 2.11).

Table 1

Characteristics of Deceased Participants in the Three National Samples

\begin{tabular}{|c|c|c|c|}
\hline Variable & SOEP & BHPS & HRS \\
\hline$N_{\text {persons }}$ & 2,764 & 2,030 & 6,195 \\
\hline Last years of death recorded & 2006 & 2006 & 2006 \\
\hline Women $(\%)$ & 48 & 52 & 54 \\
\hline Birth cohorts & $1888-1982$ & 1894-1989 & $1890-1969$ \\
\hline \multicolumn{4}{|l|}{ Age at death } \\
\hline$M(S D)$ & $72.24(14.48)$ & $75.09(13.93)$ & $79.81(10.62)$ \\
\hline Range & $20-101$ & $16-107$ & $35-111$ \\
\hline \multicolumn{4}{|l|}{ Number of waves } \\
\hline$M(S D)$ & $8.35(5.54)$ & $5.41(3.98)$ & $3.05(1.64)$ \\
\hline Range & $1-22$ & $1-15$ & $1-6$ \\
\hline $3+$ waves $(\%)$ & 88 & 68 & 57 \\
\hline Between-wave attrition $(\%)^{\mathrm{a}}$ & $4-14$ & $1-12$ & $6-8$ \\
\hline \multicolumn{4}{|c|}{ Distance first assessment to death } \\
\hline$M(S D)$ & $9.32(5.49)$ & $6.43(4.24)$ & $6.43(3.47)$ \\
\hline Range & $1-22$ & $0-15$ & $0-13$ \\
\hline \multicolumn{4}{|c|}{ Distance last assessment to death } \\
\hline$M(S D)$ & $1.95(2.58)$ & $1.77(2.02)$ & $2.14(2.12)$ \\
\hline Range & $0-16$ & $0-15$ & $0-13$ \\
\hline$N_{\text {observations }}$ & 22,672 & 10,981 & 18,520 \\
\hline \multicolumn{4}{|l|}{$\begin{array}{l}\text { Cobservations } \\
\text { Chronological age }\end{array}$} \\
\hline$M(S D)$ & $65.84(14.34)$ & 70.17 (13.74) & $75.31(10.42)$ \\
\hline Range & $19-100$ & 15-99 & $25-110$ \\
\hline $50-90$ years $(\%)$ & 86 & 89 & 94 \\
\hline \multicolumn{4}{|l|}{ Distance-to-death } \\
\hline$M(S D)$ & $7.04(4.86)$ & $5.30(3.60)$ & $4.93(3.15)$ \\
\hline Range & $22-0$ & $15-0$ & $13-0$ \\
\hline Last 10 years $(\%)$ & 77 & 89 & 95 \\
\hline
\end{tabular}

Note. $\quad$ SOEP $=$ German Socio-Economic Panel Study; BHPS $=$ British Household Panel; HRS $=$ U.S. Health and Retirement Study.

${ }^{a}$ Calculated across various subsamples, between-wave attrition is annual in the SOEP and the BHPS and biannual in the HRS. In our analyses, we included now-deceased participants from national panel studies of some 40,000 persons in Germany (SOEP); some 30,000 persons from England, Wales, Scotland, and Northern Ireland (BHPS); and some 25,000 persons from states throughout the United States (HRS). 
Time metrics of age and distance-to-death. Age at each wave was calculated as the number of years since an individual's birth (centered at 75 years). Distance-to-death at each occasion was calculated as the difference between the year of assessment and the year of an individual's death, obtained either directly from the participants' household or neighbors during the yearly interview (SOEP and BHPS) or from city or national registries or offices (e.g., U.S. National Death Index for HRS). Both time metrics were coded by integer number of years. ${ }^{1}$

\section{Growth Models}

The main analytic task was to determine whether models articulating the terminal decline hypothesis, two phases of change over distance-to-death, provided a better representation of observed changes in well-being than the more typical age-based, singlephase models of change. Separately for each study, we assessed and compared relative fits of two sets of growth models.

The age-related change models were specified as

$$
W B_{t i}=\beta_{0 i}+\beta_{1 i}\left(A G E_{t i}\right)+\beta_{2 i}\left(A G E_{t i}^{2}\right)+e_{t i},
$$

where person $i$ 's reported well-being at time $t, W B_{t i}$, is a function of an individual-specific intercept parameter, $\beta_{0 i}$, individualspecific linear and quadratic slope parameters, $\beta_{1 i}$ and $\beta_{2 i}$, that capture the rate and acceleration of change per year, and residual error, $e_{t i}$. Applying standard multilevel, latent growth modeling procedures, individual-specific intercepts, $\beta_{0 i}$, and slopes, $\beta_{1 i}$ and $\beta_{2 i}$ (from the Level 1 model given in Equation 1), were modeled as

$$
\begin{aligned}
& \beta_{0 i}=\gamma_{00}+u_{0 i}, \\
& \beta_{1 i}=\gamma_{01}+u_{1 i}, \text { and } \\
& \beta_{2 i}=\gamma_{02}
\end{aligned}
$$

(i.e., Level 2 model), where $\gamma_{00}, \gamma_{01}$, and $\gamma_{02}$ are sample means and $u_{0 i}$ and $u_{1 i}$ are individual deviations from those means that are assumed to be normally distributed, correlated with each other, and uncorrelated with the residual errors, $e_{i t}$. Deviations for the quadratic slope, $u_{2 i}$ were examined but were not significant and thus not included in the final models.

Notions of terminal decline were invoked with extensions (Cudeck \& Harring, 2007; Cudeck \& Klebe, 2002) of multiphase or "spline" growth models (Ram \& Grimm, 2007; Singer \& Willett, 2003 ) with a distance-to-death, $D t D$, time variable. Specifically, models were specified as

$$
\begin{aligned}
& W B_{t i}=\beta_{0 i}+\beta_{1 i}\left(D t D_{t i}-k\right)+e_{t i}, \text { when } D t D_{t i}<k, \text { and } \\
& W B_{t i}=\beta_{0 i}+\beta_{2 i}\left(D t D_{t i}-k\right)+e_{t i}, \text { when } D t D_{t i} \geq k,
\end{aligned}
$$

where individual-specific rates of change in the preterminal phase are captured by $\beta_{1 i}$ and individual-specific rates of change after the transition point (i.e., terminal phase) are captured by $\beta_{2 i}$. The point of transition from one phase to the other, $k$, is a free (fixed effect) parameter estimated from the data, with $\beta_{\mathrm{O} i}$ capturing individuals' estimated level of well-being at this transition point. As in the age-related change model, we modeled interindividual differences using the Level 2 model (e.g., Equation 2), where $u_{0 i}, u_{1 i}$, and $u_{2 i}$ are assumed to be normally distributed, correlated with each other, and uncorrelated with the residual errors, $e_{i t}$. We fit models to the data using SAS PROC MIXED or PROC NLMIXED. Using the accelerated longitudinal design and associated missing-at-random assumptions, we treated all the individual data segments within a study as a single homogeneous sample (Little \& Rubin, 1987; McArdle \& Bell, 2000). Model inferences are most relevant for the 50-90 years age span and/or the decade prior to death. The correlation between age and distance-to-death was of moderate size $(r<.28$ across studies, $p s<.001)$, suggesting that older individuals were somewhat closer to death and only partial overlap between the two time dimensions. Fit statistics and results were interpreted in relation to our two questions: Do changes in wellbeing across the adult life span conform to the multiphase pattern expected by terminal decline? If so, when does terminal decline prototypically begin?

\section{Results}

In all three studies, the repeated measures of well-being exhibited substantial within-person variation over time (SOEP: 55\%; BHPS: 47\%; HRS: 49\%). We used two sets of growth models, age-related change and terminal decline, to describe and evaluate how this within-person variation was structured. Table 2 reports parameter estimates and fit statistics.

\section{Age-Related Change}

Across studies, results from the age-related change models suggest stability or relatively shallow declines in well-being during adulthood and old age. As seen in Table 2, the cognitive-evaluative measure used in the SOEP showed an average rate of linear decline of $-0.26 T$ units per year, and the emotional-affective measures in the BHPS and the HRS on average declined linearly by -0.08 and $-0.10 T$ units per year, respectively. Additionally, as seen in Figure $1 \mathrm{~A}$, the normative trends in all three samples had a small amount of negative quadratic curvature, indicating some slight accommodation of lower scores in old age.

\section{Age-Related Change Versus Terminal Decline}

These single-phase, age-related models were then compared with the two-phase, distance-to-death models of terminal decline. As seen in the fit statistics reported in Table 2, the terminal decline models had better relative fit in all three data sets. Specifically, the lower Akaike information criterion (AIC; e.g., SOEP: AIC = $158,654$ vs. 160,355$)$ and the proportional reduction of prediction error (i.e., a pseudo- $R^{2}$ measure; Snijders \& Bosker, 1999; SOEP: .216 vs. .091) both indicate that the terminal decline models fit the data better than the age-related models. In sum, the results suggest that changes in well-being across the adult life span do conform to the multiphase pattern expected by terminal decline.

\section{Terminal Decline}

Examining Table 2, one can note correspondence between the linear slope in the age-related change models (e.g., SOEP: -0.26

\footnotetext{
${ }^{1}$ This was a data protection regulation for Germany. To minimize methodological variations between studies, timing of death for BHPS and HRS participants was also granulated to year (rather than using day and month precision).
} 
Table 2

Growth Models Over Chronological Age and Distance-to-Death for Well-Being in the Three National Samples

\begin{tabular}{|c|c|c|c|c|c|c|c|c|c|c|c|c|}
\hline \multirow[b]{3}{*}{ Parameter } & \multicolumn{4}{|c|}{ SOEP } & \multicolumn{4}{|c|}{ BHPS } & \multicolumn{4}{|c|}{ HRS } \\
\hline & \multicolumn{2}{|c|}{ Age } & \multicolumn{2}{|c|}{ Distance-to-death } & \multicolumn{2}{|c|}{ Age } & \multicolumn{2}{|c|}{ Distance-to-death } & \multicolumn{2}{|c|}{ Age } & \multicolumn{2}{|c|}{ Distance-to-death } \\
\hline & Estimate & $S E$ & Estimate & $S E$ & Estimate & $S E$ & Estimate & $S E$ & Estimate & $S E$ & Estimate & $S E$ \\
\hline \multicolumn{13}{|l|}{ Fixed effects } \\
\hline Intercept, $\gamma_{00}$ & $48.81^{*}$ & 0.19 & $50.36^{*}$ & 0.19 & $49.43^{*}$ & 0.20 & $50.45^{*}$ & 0.25 & $50.32^{*}$ & 0.13 & $49.57^{*}$ & 0.17 \\
\hline Linear slope $1, \gamma_{01}$ & $-0.26^{*}$ & 0.02 & $-0.22^{*}$ & 0.02 & $-0.08^{*}$ & 0.02 & $-0.18^{*}$ & 0.05 & $-0.10^{*}$ & 0.01 & $-0.29^{*}$ & 0.03 \\
\hline Quadratic slope, $\gamma_{02}$ & $-0.005^{*}$ & 0.000 & - & - & -0.001 & 0.001 & - & - & $-0.005^{*}$ & 0.001 & - & - \\
\hline Transition point, $k$ & - & - & $-4.27^{*}$ & 0.10 & - & - & $-4.85^{*}$ & 0.18 & - & - & $-2.92^{*}$ & 0.20 \\
\hline Linear slope $2, \gamma_{02}$ & - & - & $-1.31^{*}$ & 0.08 & - & - & $-0.66^{*}$ & 0.08 & - & - & $-0.88^{*}$ & 0.10 \\
\hline \multicolumn{13}{|l|}{ Random effects } \\
\hline Variance intercept & $61.69^{*}$ & 2.70 & $62.06^{*}$ & 2.52 & $51.39^{*}$ & 2.50 & $66.82^{*}$ & 3.33 & $47.08^{*}$ & 1.53 & $62.92^{*}$ & 2.22 \\
\hline Variance linear slope 1 & $0.10^{*}$ & 0.01 & $0.37^{*}$ & 0.03 & $0.06^{*}$ & 0.01 & $0.65^{*}$ & 0.09 & $0.06^{*}$ & 0.01 & $0.55^{*}$ & 0.07 \\
\hline Variance linear slope 2 & - & - & $4.90^{*}$ & 0.41 & - & - & $4.02^{*}$ & 0.48 & - & - & $4.30^{*}$ & 0.92 \\
\hline Covariance intercept, slope 1 & $1.22^{*}$ & 0.12 & $2.70^{*}$ & 0.25 & 0.23 & 0.12 & $3.81^{*}$ & 0.46 & $-0.19^{*}$ & 0.07 & $2.71^{*}$ & 0.35 \\
\hline Covariance intercept, slope 2 & - & - & $-4.81^{*}$ & 0.72 & - & - & $-5.72^{*}$ & 0.88 & - & - & $-3.51^{*}$ & 1.04 \\
\hline Covariance slope 1 , slope 2 & - & - & -0.16 & 0.09 & - & - & $-0.30^{*}$ & 0.15 & - & - & -0.31 & 0.20 \\
\hline Residual variance & $51.76^{*}$ & 0.54 & $44.57^{*}$ & 0.49 & $46.77^{*}$ & 0.74 & $37.92^{*}$ & 0.64 & $48.67^{*}$ & 0.64 & $42.43^{*}$ & 0.71 \\
\hline Pseudo- $R^{2}$ reduction & \multirow{2}{*}{\multicolumn{2}{|c|}{$\begin{array}{c}.091 \\
160.341\end{array}$}} & \multicolumn{2}{|c|}{.216} & \multicolumn{2}{|c|}{.033} & \multicolumn{2}{|c|}{.215} & \multicolumn{2}{|c|}{.031} & \multicolumn{2}{|c|}{.156} \\
\hline-2 log-likelihood & & & \multirow{2}{*}{\multicolumn{2}{|c|}{$\begin{array}{l}158,632 \\
158,654\end{array}$}} & \multirow{2}{*}{\multicolumn{2}{|c|}{$\begin{array}{l}77,217 \\
77,231\end{array}$}} & \multirow{2}{*}{\multicolumn{2}{|c|}{$\begin{array}{l}76,444 \\
76,466\end{array}$}} & \multirow{2}{*}{\multicolumn{2}{|c|}{$\begin{array}{l}133,06 / \\
133,081\end{array}$}} & \multirow{2}{*}{\multicolumn{2}{|c|}{$\begin{array}{l}132,593 \\
132,615\end{array}$}} \\
\hline AIC & \multicolumn{2}{|c|}{160,355} & & & & & & & & & & \\
\hline
\end{tabular}

Note. Unstandardized estimates and standard errors are presented. Scores are standardized to a $T$ metric with all decedent observations available in each study as the reference frame; intercepts are centered at age 75 for the age-related models and at the transition point for the distance-to-death models; slope or rate of change is scaled in $T$ units per year. Dashes indicate that the respective model parameter was not estimated. SOEP = German Socio-Economic Panel Study; BHPS = British Household Panel Study; HRS = U.S. Health and Retirement Study; AIC = Akaike information criterion. ${ }^{*} p<.05$. 
(A)

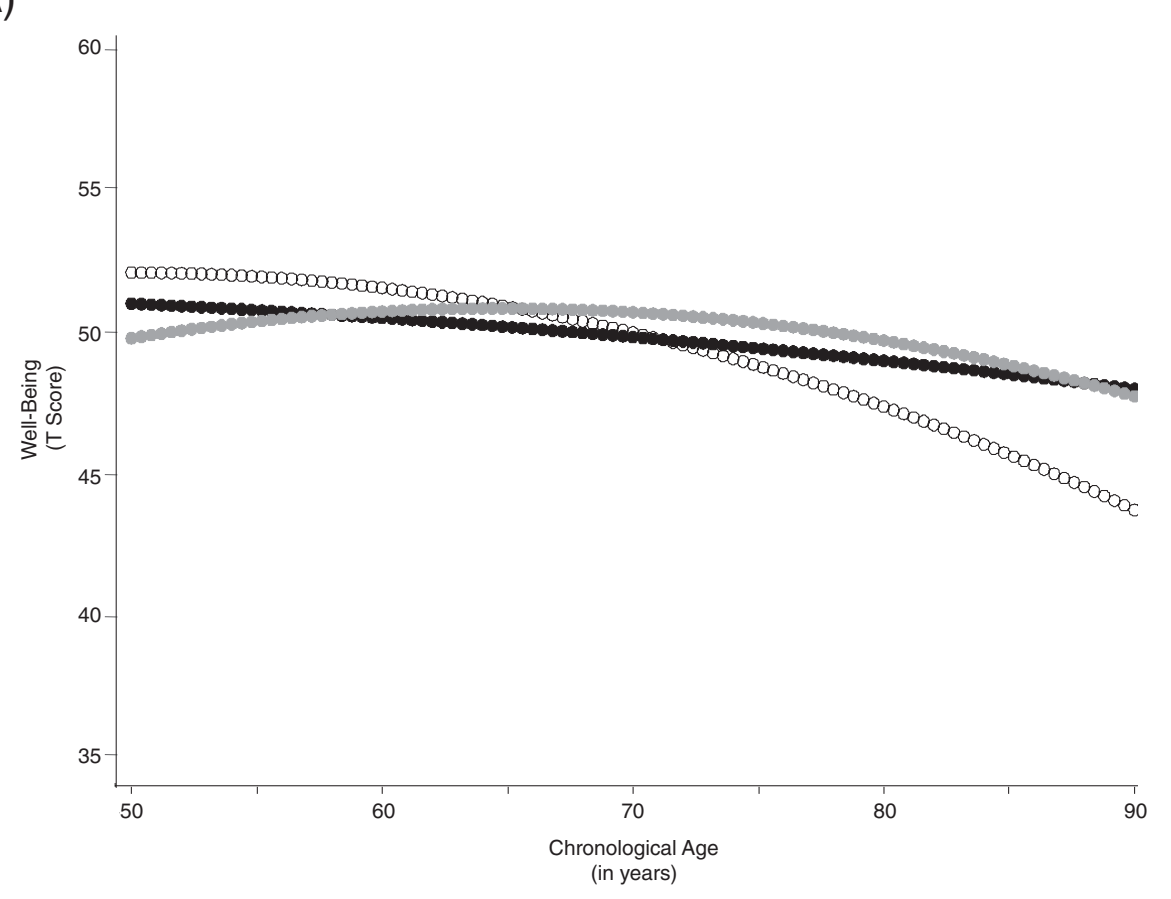

(B)

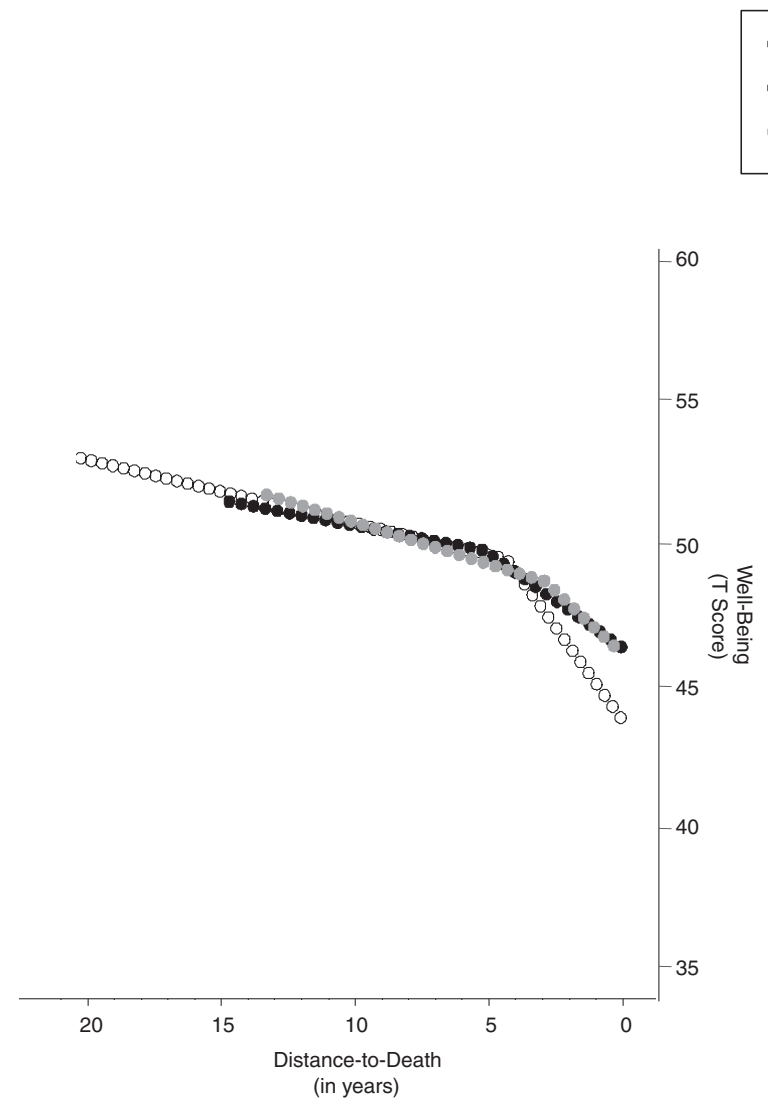

Figure 1. Prototypical rates of well-being decline observed over chronological age (A) and distance-to-death (B). Consistently across data from three national studies in Germany, the United Kingdom, and the United States, well-being was relatively stable over age but declined rapidly with impending death. After the onset of a terminal phase between 3 and 5 years prior to death, well-being decline steepened by a factor of three or more. 
$T$ units per year) and the preterminal slopes in the terminal decline models (e.g., SOEP: $-0.22 T$ units per year). As seen in Figure 1B, this relative stability in well-being contrasts sharply with the prototypical decline in the terminal phase in all three studies (SOEP: $-1.31 T$ units per year) wherein well-being appears to drop sharply into death. ${ }^{2}$ The two-phase model allowed for empirical identification of when, on average, the terminal phase of decline begins. Across studies, the point of "transition" was estimated to be between 3 and 5 years prior to death $(\mathrm{SOEP}=4.27$; BHPS $=4.85 ;$ HRS $=2.92$ ).

\section{Discussion}

The purpose of this study was to examine whether average changes in well-being across adulthood conform to the pattern expected by notions of terminal decline and, if so, when the terminal phase of decline prototypically begins. Using long-term longitudinal data from decedents in three nationally representative studies in Germany, the United Kingdom, and the United States, we consistently found greater proportions of explained variance for models articulating the terminal decline hypothesis, relative to typical age-based models. In line with theories of self-regulation (Brickman \& Campbell, 1971) and successful aging (Carstensen, 2006) and the myriad of empirical reports (see Diener et al., 2006), our age-related results indicate mean-level stability or minor decline in well-being across adulthood and old age. Our findings, however, also consistently suggest some qualification to this prevailing picture. Well-being does not, on average, appear to be stable in the last years of life. Charting well-being in relation to the years left in life rather than over the years lived revealed, consistent with theoretical notions of terminal decline, alarmingly steep prototypical proximate-to-death deteriorations in well-being that span 3-5 years.

Our findings add to recent reports that major life events such as widowhood result in long-lasting well-being changes (e.g., lower levels persist over time; Headey, 2008; Lucas, 2007) and suggest that impending death denotes another major life event that contributes to systematic well-being changes, albeit ones that lead up to the event rather than result from it. In line with this view, the findings are interpreted to indicate that mortality-related mechanisms or other progressive processes leading toward death (e.g., deteriorating health) overwhelm the regulatory or motivational mechanisms that usually keep well-being stable and become the prime drivers of late-life decline in well-being. More generally, our findings highlight the need to consider when and how mortality or other selection processes contribute to observed changes (Hertzog \& Nesselroade, 2003; Lindenberger, Singer, \& Baltes, 2002) and the need for further refinement of concepts about when and how late-life declines in psychosocial functioning typically begin and proceed.

Seminal notions of terminal decline have proposed that the last months or years of life are characterized by a phase of rapid decline wherein mortality-related processes compromise integral aspects of function (Kleemeier, 1962). Consistent with this general proposal, our mortality-related models portray a normative picture of well-being change, with individuals transitioning from a preterminal age-dominated phase of minor decline to a terminal mortality-dominated phase of steep decline. The replication and generalization across nations provides further evidence that exac- erbated rates of end-of-life declines are not specific to intellectual and sensory functioning (Bäckman \& MacDonald, 2006; MacDonald, Hultsch, \& Dixon, 2008) but also extend to subjective well-being. Further, late-life declines in well-being are not restricted to individuals who died in old age (Gerstorf, Ram, Estabrook, et al., 2008; Gerstorf, Ram, Röcke, et al., 2008) but are also found when all adult decedents, no matter their age of death, are examined. ${ }^{3}$ This is notable because middle-aged adults, relative to older people, may have a larger pool of resources to draw from and thereby might be better able to ward off the detrimental effects of impending death. More in-depth work is of course necessary to thoroughly examine such age-differential questions, but our evidence illustrates the pervasive nature of mortalityrelated processes.

Theoretical notions have been vague about when end-of-life decrements can typically be expected to begin or how they may proceed across domains of function (Birren \& Cunningham, 1985). Thus, to inform future theoretical specification regarding the timing of terminal decline, we used models that allowed for empirical localization of the average onset of transition to the terminal phase of life. Treating the three national samples as independent replications, we found, despite only partial overlap at the measurement level, strikingly similar construct-level findings. Prototypically, terminal decline in well-being appears to span the last 3-5 years of life.

Despite apparent across-nation similarities, however, we also observed notable differences in the amount of average mortalityrelated decline, with stronger prototypical decrements in the SOEP than in the BHPS or HRS. Differences in measurement scales, reliability of those scales, whether those scales tapped cognitiveevaluative or emotional aspects of well-being, study sampling and maintenance procedures, and the timing of observations discourage comparisons beyond the general pattern of findings. As a consequence, inferences regarding differences between national trends or between specific aspects of well-being are not warranted. Given that we are only at the very beginning of understanding the etiological nature of mortality-related decline in well-being, we interpret the consistency of results across the three studies as national-level replications. A better understanding will be obtained when we are able to pinpoint within-person processes more specifically and identify the roles that individual factors (e.g., physical

\footnotetext{
${ }^{2}$ Consistent with the general pattern of results, a single-phase model over distance-to-death revealed more efficient descriptions than a singlephase model over age (SOEP: pseudo- $R^{2}$ reduction $=.150$; BHPS: pseudo- $R^{2}$ reduction $=.138$; HRS: pseudo- $R^{2}$ reduction $=.110$ ). However, the two-phase models over distance-to-death still provided better relative model fit than the single-phase models over distance-to-death (SOEP: $\Delta$ AIC $=466$; BHPS: $\Delta$ AIC $=236$; HRS: $\Delta$ AIC $=44)$. We note that observations outside the $50-90$ years age span or 20 or more years prior to death were not graphed in Figure 1 because of scarce data across these ages.

${ }^{3}$ Including all participants (independent of their mortality status) when estimating age-related models resulted in somewhat shallower age gradients (e.g., $N=20,263$ SOEP participants: linear slope $=-0.16$, quadratic slope $=-0.001$, both $p$ s $<.05$ or below). The general pattern of results was also found in all three studies when we restricted the samples to those who died before age 70 (e.g., $N=1,024$ SOEP participants: pseudo- $R^{2}$ reduction in age model $=.081$ vs. distance-to-death model $=.203$ ).
} 
and mental health, disease and other causes of death, social relations) and community or societal factors (e.g., health and social infrastructure) play in the onset and progression of terminal decline (or stability).

In our study, we have applied contemporary methods to articulate and test long-standing conceptual notions of terminal decline (Kleemeier, 1962). In line with those notions, well-being remained, on average, relatively stable with age and declined rapidly with impending death. Conceptually, this pattern provides a rather disconcerting image of late-life psychological health that qualifies notions of successful aging (Rowe \& Kahn, 1997; see Baltes, 2006) and highlights the need for identifying and targeting via intervention potential moderators (e.g., accumulating disability, Verbrugge \& Jette, 1994; cognitive terminal decline, Small \& Bäckman, 1999) that may account for interindividual differences in how well-being changes in late life. We also note that even such extended longitudinal data as were available here constrain which aspect of late-life change we could study. We prioritized to determine the "average" population-level estimates for locating the onset of terminal decline, making the strict assumption that the transition point is invariant across individuals. Relaxing this assumption requires a larger density of observations, probably measuring people several times a year until death (see second analysis in Gerstorf, Ram, Estabrook, et al., 2008). ${ }^{4}$ Finally, we modeled developmental change as a function of a future event, death, such that death serves as a retroactive cause for the observed decline. Ideally, we would like to test in a prospective manner whether observed decline is predictive of the unknown subsequent event of death, which would require an additional shift in data-analytic perspective from our descriptive models to a more complex set of predictive models (see Ghisletta, McArdle, \& Lindenberger, 2006).

The deteriorating late-life psychological health found in this three-nation study suggests that the societal burden and personal costs of dying may span the last 3-5 years of life. Given the alarmingly steep end-of-life declines that individuals typically face, a better understanding of when and how terminal declines begin and proceed is warranted. Further knowledge is needed about why some persons may experience fewer declines or a later onset of decline prior to death. Such inquiries will help identify those pathways by which more individuals can, in the face of seemingly inevitable decline, remain happy until the end.

\footnotetext{
${ }^{4}$ Using data from a subsample of 400 SOEP participants who provided between 12 and 25 annual reports and models that allow for interindividual differences in the timing of the transition to terminal decline, we found considerable between-persons differences in the location of the transition point. Although 12 measurement occasions might serve as a rough minimum number of occasions needed for estimating such models, many more occasions are preferable.
}

\section{References}

Argyle, M. (1999). Correlates and consequences of happiness. In D. Kahneman, E. Diener, \& N. Schwarz (Eds.), Well-being: The foundations of hedonic psychology (pp. 353-373). New York, NY: Sage.

Bäckman, L., \& MacDonald, S. W. S. (2006). Death and cognition: Synthesis and outlook. European Psychologist, 11, 224-235.
Baltes, P. B. (2006). Facing our limits: Human dignity in the very old. Daedalus, 135, 33-39.

Birren, J. E., \& Cunningham, W. R. (1985). Research on the psychology of aging: Principles, concepts and theory. In J. E. Birren \& K. W. Schaie (Eds.), Handbook of the psychology of aging (2nd ed., pp. 3-34). New York, NY: Van Nostrand Reinhold.

Brandstädter, J. (1999). Sources of resilience in the aging self: Toward integrating perspectives. In T. M. Hess \& F. Blanchard-Fields (Eds.), Social cognition and aging (pp. 123-141). San Diego, CA: Academic Press.

Brickman, P., \& Campbell, D. T. (1971). Hedonic relativism and planning the good society. In M. Appley (Ed.), Adaptation-level theory: A symposium (pp. 287-305). New York, NY: Academic Press.

Burkhauser, R. V., \& Gertler, P. J. (1995). Introduction: Special Issue on the Health and Retirement Survey: Data quality and early results. Journal of Human Resources, 30, S1-S6.

Carstensen, L. L. (2006, June 30). The influence of a sense of time on human development. Science, 312, 1913-1915.

Carstensen, L. L., Pasupathi, M., Mayr, U., \& Nesselroade, J. R. (2000). Emotional experience in everyday life across the adult life span. Journal of Personality and Social Psychology, 79, 644-655.

Charles, S. T., Reynolds, C. A., \& Gatz, M. (2001). Age-related differences and change in positive and negative affect over 23 years. Journal of Personality and Social Psychology, 80, 136-151.

Costa, P. T., Jr., Zonderman, A. B., McCrae, R. R., Cornoni-Huntley, J., Locke, B. Z., \& Barbano, H. E. (1987). Longitudinal analyses of psychological wellbeing in a national sample: Stability of means levels. Journal of Gerontology, 42, 50-55.

Cudeck, R., \& Harring, J. R. (2007). Analysis of nonlinear patterns of change with random coefficient models. Annual Review of Psychology, $58,615-637$.

Cudeck, R., \& Klebe, K. J. (2002). Multiphase mixed-effects models for repeated measure data. Psychological Methods, 7, 41-63.

Danner, D. D., Snowdon, D. A., \& Friesen, W. V. (2001). Positive emotions in early life and longevity: Findings from the Nun Study. Journal of Personality and Social Psychology, 80, 804-813.

Diener, E., Lucas, R. E., \& Scollon, C. N. (2006). Beyond the hedonic treadmill: Revising the adaptation theory of well-being. American Psychologist, 61, 305-314.

Diener, E., \& Suh, E. M. (1997). Subjective well-being and age: An international analysis. In K. W. Schaie \& M. P. Lawton (Eds.), Annual Review of Gerontology and Geriatrics: Vol. 17. Focus on emotion and adult development (pp. 304-324). New York, NY: Springer.

Diener, E., Suh, E. M., Lucas, R. E., \& Smith, H. L. (1999). Subjective well-being: Three decades of progress. Psychological Bulletin, 125, 276-302.

Fujita, F., \& Diener, E. (2005). Life satisfaction set point: Stability and change. Journal of Personality and Social Psychology, 88, 158-164.

Gerstorf, D., Ram, N., Estabrook, R., Schupp, J., Wagner, G. G., \& Lindenberger, U. (2008). Life satisfaction shows terminal decline in old age: Longitudinal evidence from the German Socio-Economic Panel Study (SOEP). Developmental Psychology, 44, 1148-1159.

Gerstorf, D., Ram, N., Röcke, C., Lindenberger, U., \& Smith, J. (2008). Decline in life satisfaction in old age: Longitudinal evidence for links to distance-to-death. Psychology and Aging, 23, 154-168.

Ghisletta, P., McArdle, J. J., \& Lindenberger, U. (2006). Longitudinal cognition-survival relations in old and very old age: 13-year data from the Berlin Aging Study. European Psychologist, 11, 204-223.

Goldberg, D. P. (1978). Manual of the General Health Questionnaire. Windsor, England: NFER Nelson.

Griffin, P. W., Mroczek, D. K., \& Spiro, A., III. (2006). Variability in affective change among aging men: Longitudinal findings from the VA Normative Aging Study. Journal of Research in Personality, 40, 942 965. 
Guralnik, J. M. (1991). Prospects for the compression of morbidity: The challenge posed by increasing disability in the years prior to death. Journal of Aging and Health, 3, 138-154.

Haynie, D. A., Berg, S., Johannson, B., Gatz, M., \& Zarit, S. H. (2001). Symptoms of depression in the oldest old: A longitudinal study. Journals of Gerontology: Series B. Psychological Sciences and Social Sciences, 56B, P111-P118.

Headey, B. (2008). Life goals matter to happiness: A revision of set-point theory. Social Indicators Research, 86, 213-231.

Hertzog, C., \& Nesselroade, J. R. (2003). Assessing psychological change in adulthood: An overview of methodological issues. Psychology and Aging, 18, 639-657.

Hu, Y., Stewart-Brown, S., Twigg, L., \& Weich, S. (2007). Can the 12-item General Health Questionnaire be used to measure positive mental health? Psychological Medicine, 37, 1005-1013.

Kleemeier, R. W. (1962). Intellectual changes in the senium. Proceedings of the Social Statistics Section of the American Statistical Association, 1, 290-295.

Kunzmann, U. (2008). Differential age trajectories of positive and negative affect: Further evidence from the Berlin Aging Study. Journals of Gerontology: Series B. Psychological Sciences and Social Sciences, 63, P261-P270.

Kunzmann, U., Little, T. D., \& Smith, J. (2000). Is age-related stability of subjective well-being a paradox? Cross-sectional and longitudinal evidence from the Berlin Aging Study. Psychology and Aging, 15, 511526

Larson, R. (1978). Thirty years of research on the subjective well-being of older Americans. Journal of Gerontology, 33, 109-125.

Levy, B. R., Slade, M. D., Kunkel, S. R., \& Kasl, S. V. (2002). Longevity increased by positive self-perceptions of aging. Journal of Personality and Social Psychology, 83, 261-270.

Lindenberger, U., Singer, T., \& Baltes, P. B. (2002). Longitudinal selectivity in aging populations: Separating mortality-associated versus experimental components in the Berlin Aging Study (BASE). Journals of Gerontology: Series B. Psychological Sciences and Social Sciences, 57, P474-P482.

Little, R. J. A., \& Rubin, D. B. (1987). Statistical analysis with missing data. New York, NY: Wiley.

Lucas, R. E. (2007). Adaptation and the set-point model of subjective well-being: Does happiness change after major life events? Current Directions in Psychological Science, 16, 75-79.

MacDonald, S. W. S., Hultsch, D. F., \& Dixon, R. A. (2008). Predicting impending death: Inconsistency in speed is a selective and early marker. Psychology and Aging, 23, 595-607.

Maier, H., \& Smith, J. (1999). Psychological predictors of mortality in old age. Journals of Gerontology: Series B. Psychological Sciences and Social Sciences, 54, P44-P54.

McArdle, J. J., \& Bell, R. Q. (2000). An introduction to latent growth models for developmental data analysis. In T. D. Little, K. U. Schnabel, \& J. Baumert (Eds.), Modeling longitudinal and multiple-group data:
Practical issues, applied approaches, and scientific examples (pp. 69107). Mahwah, NJ: Erlbaum.

Mroczek, D. K., \& Kolarz, C. M. (1998). The effect of age on positive and negative affect: A developmental perspective on happiness. Journal of Personality and Social Psychology, 75, 1333-1349.

Mroczek, D. K., \& Spiro, A., III. (2005). Change in life satisfaction during adulthood: Findings from the Veterans Affairs Normative Aging Study. Journal of Personality and Social Psychology, 88, 189-202.

Myers, D. (1992). The pursuit of happiness: Who is happy—and why. New York, NY: Morrow.

Radloff, L. W. (1977). The CES-D Scale: A self-report depression scale for research in the general population. Applied Psychological Measurement, 1, 385-401.

Ram, N., \& Grimm, K. J. (2007). Using simple and complex growth models to articulate developmental change: Matching theory to method. International Journal of Behavioral Development, 31, 303-316.

Riegel, K. F., \& Riegel, R. M. (1972). Development, drop, and death. Developmental Psychology, 6, 306-419.

Rowe, J. W., \& Kahn, R. L. (1997). Successful aging. Gerontologist, 37, 433-440.

Schilling, O. (2006). Development of life satisfaction in old age: Another view on the paradox. Social Indicator Research, 75, 241-271.

Singer, J. D., \& Willett, J. B. (2003). Applied longitudinal data analysis: Modeling change and event occurrence. New York, NY: Oxford University Press.

Sliwinski, M. J., Stawski, R. S., Hall, C. B., Katz, M., Verghese, J., \& Lipton, R. (2006). Distinguishing preterminal and terminal cognitive decline. European Psychologist, 11, 172-181.

Small, B. J., \& Bäckman, L. (1999). Time to death and cognitive performance. Current Directions in Psychological Science, 8, 168-172.

Snijders, T. A. B., \& Bosker, R. J. (1999). Multilevel analysis: An introduction to basic and advanced multilevel modeling. London, England: Sage.

Suzman, R. M., Willis, D. P., \& Manton, K. G. (Eds.). (1992). The oldest old. New York, NY: Oxford University Press.

Taylor, M. F., Brice, J., Buck, N., \& Prentice-Lane, E. (Eds.). (2008). British Household Panel Survey user manual Volume A: Introduction, technical report and appendices. Colchester, England: University of Essex.

Verbrugge, L. M., \& Jette, A. M. (1994). The disablement process. Social Science and Medicine, 38, 1-14.

Wagner, G. G., Frick, J. R., \& Schupp, J. (2007). Enhancing the power of household panel studies: The case of the German Socio-Economic Panel Study (SOEP). Schmollers Jahrbuch, 127, 139-169.

Wilson, R. S., Beckett, L. A., Bienias, J. L., Evans, D. A., \& Bennett, D. A. (2003). Terminal decline in cognitive function. Neurology, 60, 17821787.

Received February 18, 2009

Revision received June 18, 2009

Accepted September 4, 2009 